\title{
Inclusão de estudantes com deficiências na universidade: Estudo em uma universidade portuguesa
}

\author{
Ana Claudia Rodrigues Fernandes \\ Universidade de Brasília - Brasília - DF - Brasil \\ Maria Cláudia Santos Lopes de Oliveira \\ Universidade de Brasília - Brasília - DF - Brasil \\ Leandro da Silva Almeida \\ Universidade do Minho - Braga - Portugal
}

\begin{abstract}
Resumo
Contemporaneamente o ensino superior é considerado um contexto implicado na promoção da cidadania, além da formação acadêmica e profissional, em que a inclusão de pessoas com deficiência se torna questão de crescente importância. Neste artigo apresentamos os resultados de um estudo que teve como objetivo explorar as concepções de oito estudantes de uma universidade de Portugal sobre os desafios enfrentados ao experimentarem a inclusão nesse nível de ensino. A coleta de dados envolveu entrevistas semi-estruturadas individuais e questionário online, analisados de acordo com um sistema de categorização aberto. Os resultados informam que no ambiente da universidade há pouco conhecimento disponível sobre o tema da diversidade e da inclusão entre docentes e estudantes, em geral; os serviços institucionais de apoio aos estudantes com deficiência existentes carecem de eficácia em distintos aspectos. Desse modo, discute-se, a partir da experiência dos estudantes investigados, a necessidade de se promover uma cultura inclusiva que previna preconceito e favoreça a autonomia e a cidadania. Aponta-se a importância de estudos futuros que expandam o debate sobre inclusão no ensino superior.
\end{abstract}

Palavras-chave: Ensino Superior; deficiências; inclusão.

\section{Inclusion of students with disabilities at the University: Study in a Portuguese university}

\begin{abstract}
Contemporaneously higher education is considered an implied context in promoting citizenship, as well as academic and professional, in which the inclusion of people with disabilities becomes increasingly important issue. This article presents the results of a study aimed to explore the concepts of eight students of a university in Portugal about the challenges they faced in trying to be part in the process of inclusion in this level of education. Data collection involved individual semi-structured interviews and online survey, analyzed according to an open system of categorization. The results report that the university environment has little knowledge available on the subject of diversity and inclusion between teachers and students in general; institutional support services for students with disabilities existing has a lack of efficacy in different aspects. Thus, it is argued, from the experience of the investigated students, the need to promote an inclusive culture that prevents prejudice and promotes the autonomy and citizenship. It points out the importance of future studies that expand the debate on inclusion in higher education.
\end{abstract}

Keywords: Higher education; disabilities; inclusion.

\section{Inclusión de estudiantes con deficiencias en la universidad: Estudio en una universidad portuguesa}

\section{Resumen}

En la contemporaneidad la enseñanza superior es considerada un contexto implicado en la promoción de la ciudadanía, además de la formación académica el profesional, en que la inclusión de personas con deficiencia se vuelve cuestión de creciente importancia. En este artículo se presentan los resultados de un estudio que tuvo como objetivo explorar las concepciones de ocho estudiantes de una universidad de Portugal sobre los retos enfrentados al experimentar la inclusión en ese nivel de enseñanza. La recolecta de datos abarcó entrevistas semiestructuradas individuales y cuestionario online, analizados de acuerdo con un sistema de categorización abierto. Los resultados informan que en el ambiente de la universidad hay poco conocimiento disponible sobre el tema de la diversidad y de la inclusión entre docentes y estudiantes, en general; los servicios institucionales de apoyo a los estudiantes con deficiencia existentes carecen de eficacia en distintos aspectos. De ese modo, se discute, a partir de la experiencia de los estudiantes investigados, la necesidad de promoverse una cultura inclusiva que prevenga prejuicio y favorezca la autonomía y la ciudadanía. Se apunta la importancia de estudios futuros que expandan el debate sobre inclusión en la enseñanza superior.

Palabras clave: Educación superior; deficiencias; inclusión. 


\section{Introdução}

A Universidade, em sua concepção mais contemporânea, constitui-se como espaço privilegiado para o exercício da cidadania, possibilitando a desconstrução de modelos sociais opressores e, assim, a transformação de valores e da própria realidade (Andrade, 2010; Olive, 2002; Severino, 2008; Sousa Santos, 2005; Trindade, 2001). Da perspectiva dos estudantes, a experiência universitária é considerada um importante marcador de trajetória de desenvolvimento pessoal e social. É relevante tanto no que se refere às oportunidades concretas de formação acadêmica, quanto pelas relações sociais aí estabelecidas, desde que pautadas em posturas éticas e humanizadas (Bucuto, Almeida, \& Araújo, 2014; Marinho-Araújo, 2009, 2011).

Nesse cenário, a inclusão de estudantes com deficiências representa uma importante iniciativa da Universidade em assumir uma missão institucional em resposta às demandas. A chegada ao ensino superior leva o estudante a enfrentar uma realidade educacional nova, necessariamente mais complexa e exigente que a educação básica (Coulon, 2008; Fernandes \& Almeida, 2007). Por outro lado, fatores como ambientes pouco receptivos e desestimulantes, presença de barreiras físicas e arquitetônicas, discriminação, falta de informação, e ainda, a inexistência de serviços de apoio podem influenciar negativamente a trajetória dos jovens com algum tipo de deficiência, podendo resultar em abandono (Abreu \& Antunes, 2011; Fernandes \& Almeida, 2007). Além desses, também recaem sobre as universidades fortes expectativas de que contribuam para a diminuição das diferenças impostas pelos padrões potencialmente desiguais estabelecidos no atendimento às exigências de qualificação no mercado de trabalho, bem como para o desenvolvimento econômico e social, de modo amplo (Seixas, 2003).

A experiência universitária, face às exigências da sociedade atual, tem um papel importante no desenvolvimento pessoal e social dos indivíduos. Pode contribuir para lhes conferir novas visões de realidade, e possibilitar (re)posicionamentos identitários e recolocações espaço-temporais, transformações essas que ocorrem de forma dinâmica e negociada (Ressurreição, 2013). A partir da característica do ensino superior como educação de adultos e especificamente voltada à profissionalização, várias rupturas simultâneas tendem a ocorrer, que exigem do indivíduo adequação e afiliação ao novo contexto. Podem emergir, ainda, demandas a serem atendidas como forma de oportunizar condições adequadas de permanência e aproveitamento académico.

Tomando em consideração a relevância de ações para a promoção da inclusão e a necessidade de conhecer os sistemas com esse fim no ensino superior, discutimos o contexto inclusivo e as práticas voltadas à inclusão, a partir dos relatos feitos por estudantes em uma instituição de ensino superior em Portugal ${ }^{1}$. Assim o estudo teve como objetivo

10 presente texto apresenta resultados parciais do Estágio Doutoral (PDSE - Capes) realizado pela primeira autora em Portugal, sob supervisão e orientação dos demais autores, no período compreendido entre agosto e dezembro - 2014. conhecer as concepções de estudantes com deficiência auditiva e visual sobre os desafios da experiência universitária, bem como as suas sugestões para a melhor integração e aproveitamento.

\section{Dispositivos legais para a inclusão no ensino superior de Portugal}

Um levantamento da legislação que normatiza a inclusão escolar de pessoas com deficiências permite verificar que não há documentos específicos que orientem as ações e processos de inclusão no ensino superior português (Antunes \& Faria, 2013; Santos, 2013). A legislação existente é direcionada à educação pré-escolar, ensino básico e secundário. E, de forma geral, orienta a criação de apoios pedagógicos adequados às necessidades individuais dos estudantes com deficiência na trajetória escolar, sem mencionar orientações precisas ou as condições para o acesso e a permanência no ensino superior. Deve-se destacar, no entanto, a existência, desde 1985, de um contingente especial para candidatos com deficiência física ou sensorial, que reserva $2 \%$ das vagas do ensino superior a tais estudantes, previsto no regulamento do Concurso Nacional de Acesso ao Ensino Superior, definido pelo Ministério da Educação de Portugal (Pires, 2007; Santos, 2013).

Percebe-se hoje a crescente demanda para o acesso ao ensino superior por parte dos estudantes com deficiência. Diante dessa realidade, as Instituições de Ensino Superior têm sido convocadas a responder de modo cada vez mais satisfatório às especificidades destes estudantes. Surgem assim, em algumas instituições, políticas internas, regulamentos, programas e ações voltadas à inclusão. Essas ações refletem algumas orientações internacionais, ao mesmo tempo que existem já mais espaços de debate sobre o tema no seio da academia (Antunes \& Faria, 2013; Pires, 2007).

No campo internacional algumas iniciativas foram muito importantes, como as diretivas comunitárias da União Europeia sobre igualdade de oportunidades das pessoas com deficiências nas áreas do combate à discriminação, do emprego e atividade profissional, acesso a serviços de apoio e cuidados (Pires, 2007). Outra iniciativa foi a adoção do Plano de Ação Europeu para a Deficiência (2004-2010), que teve como princípio a aplicação de valores de não-discriminação e integração das pessoas com deficiência ou incapacidade na União Europeia. Ainda somaram-se a essas, as opções do Plano 2005-2009, aprovadas em Conselho de Ministros, em 2005, incluindo medidas para a melhoria das condições de acesso e frequência ao ensino superior em Portugal para estudantes com deficiências (Pires, 2007). Numa breve síntese, os documentos legais que definem ações inclusivas no ensino superior português são: a Constituição da República Portuguesa (1976); a Lei de Bases do Sistema Educativo (Lei n. $\left.{ }^{\circ} 46 / 86,1986\right)$; o Decreto-Lei n. ${ }^{\circ} 3 / 2008$ (2008); a Lei de Bases para o Financiamento do Ensino Superior (Lei $n .^{\circ}$ 37/2003, 2003); assim como a Lei n. ${ }^{\circ}$ 46/2006 (2006). 
A Constituição da República Portuguesa aprovada em 1971 , em seus artigos $71^{\circ}, 73^{\circ}$ e $74^{\circ}$ aborda a previsão de direitos e deveres dessa parcela da população. A Lei de Bases do Sistema Educativo (Lei n. ${ }^{\circ} 46 / 86,1986$ ) também se coaduna com tais princípios. O Decreto-Lei n. ${ }^{\circ} 3 / 2008$ (2008) organiza a educação especial, com orientações mais voltadas para a educação básica e ensino secundário, mas que destaca, dentre outras, a importância da concepção e gestão dos espaços a fim de contribuir para o sucesso educativo e escolar dos alunos. Já a Lei de Bases para o Financiamento do Ensino Superior (Lei n. ${ }^{\circ} 37 / 2003,2003$ ) estabelece que devem ser concedidos apoios específicos a estudantes com deficiência. Por fim, a Lei n. ${ }^{\circ} 46 / 2006$, pretende prevenir e coibir a discriminação, direta ou indireta, em decorrência da deficiência.

Uma iniciativa de apoio aos sistemas inclusivos nas Universidades foi a criação do Grupo de Trabalho para o Apoio a Estudantes com Deficiências no Ensino Superior (GTAEDES). O grupo tem o objetivo de partilhar experiências e definir orientações para políticas e normas para os serviços de suporte a estudantes com deficiências. O grupo é composto por instituições de educação pública, representantes da Direção-Geral do Ensino Superior (DGES), da Agência para a Sociedade do Conhecimento (Umic) e do Instituto Nacional para a Reabilitação.

Dentre as iniciativas das universidades para a inclusão, destacam-se ações como a formação contínua de professores, a adaptação de currículos, a produção de recursos pedagógicos e a criação de serviços e programas de apoio aos estudantes (Antunes \& Faria, 2013; Morejón \& Garcia, 2010). Contudo, em virtude da ausência de um marco legal regulador das medidas de apoio, as iniciativas ainda são locais e particulares de cada instituição. As universidades assumem, então, a sua responsabilidade e promovem a criação de serviços de apoio à inclusão acadêmica, aprendizagem e desenvolvimento dos estudantes com deficiências.

Quando nos referimos ao universo de estudantes que são usuários dos sistemas de apoio à inclusão, faz-se relevante destacar as especificidades apresentadas pelos sujeitos com deficiências. Tanto no tocante ao tipo de deficiência, quanto às especificidades dos sujeitos é grande a diversidade de necessidades e demandas que se fazem presentes conforme a deficiência existente. A atenção a tais especificidades e demandas dos sujeitos gera para a universidade um desafio importante para o êxito dos sistemas de apoio à inclusão. A seguir, passamos a apontar os desafios de uma universidade portuguesa em organizar seu sistema de apoio à inclusão.

\section{A implementação de programa de apoio numa universidade Portuguesa}

Um exemplo de programa estruturado para a inclusão está presente numa universidade do norte de Portugal. A universidade criou um serviço de apoio aos estudantes com deficiências, recentemente denominado Gabinete para a Inclusão (GPI). Sua criação consta do Estatuto da referida Universidade e estabelece que as Unidades de Serviços compreendem, nomeadamente, as áreas “... de apoio aos estudantes portadores de deficiência. A iniciativa da Universidade é de representar os direitos dos estudantes em seu regimento e buscar assegurar atenção a tal grupo" (GPI).

Ao especificar o trabalho do Gabinete para a Inclusão (GPI), constatamos que os serviços, conforme previstos no Regimento da Universidade, de forma geral, se focam nas seguintes ações: mediar a comunicação entre professores e alunos, relacionadas a situações específicas de cada caso; acompanhar a frequência dos estudantes às aulas e o próprio andamento das suas aprendizagens; promover a adaptação dos planos de estudos e o acompanhamento individualizado; propor regimes de avaliação individualizados, assim como o apoio documental e bibliográfico aos estudantes. $O$ plano de atividades anual do GPI aponta como ações permanentes: (i) o atendimento a estudantes com deficiência, o atendimento a professores que necessitem de orientação, o atendimento a estudantes que pretendam realizar trabalhos acadêmicos sobre o tema da deficiência; (ii) elaboração e publicação do Manual de boas práticas para a Inclusão; e (iii) estabelecimento de parcerias para a dinamização de projetos na área de atuação do gabinete.

Os documentos que tratam dos serviços prestados pelo referido gabinete destacam o quanto ele tem buscado organizar os atos, no âmbito institucional, ao buscar parcerias e promover ações de sensibilização da comunidade universitária como um todo. No âmbito individual, tem agido ao implementar ações focadas nas demandas dos estudantes, em resposta aos pedidos de apoio no respeitante às situações de vida acadêmica. A proposição desse modelo de ação visa oferecer melhores condições de permanência do estudante no ensino superior (Bisinoto \& Marinho-Araújo, 2014; Antunes \& Faria, 2013; Abreu, Antunes, \& Almeida, 2012).

Neste artigo, descrevemos as ações promovidas pelo gabinete que têm por foco as demandas individuais, uma vez que essas têm o intento de criar condições para o desenvolvimento dos estudantes com deficiência. No plano de atividades do GPI, as ações de apoio aos estudantes ocorrem como respostas aos pedidos de apoio: (i) estabelecimento de contato com docentes; (ii) esclarecimento de dúvidas e realização de ações de informação solicitadas pelos docentes; (iii) garantia de condições especiais de frequência e avaliação aos estudantes; (iv) articulação com outros serviços para a resolução de problemas; (v) empréstimo de tecnologias de apoio ou a colocação destas em sala de aula; (vi) sinalização da necessidade de eliminação de barreiras físicas; (vii) organização e encaminhamento de pedidos de vagas adicionais para transferência ou mudança de curso; (viii) acesso a materiais de estudo como digitalização e impressão em Braille.

Ponderando as ações percebemos que, de forma geral, elas representam a forma pela qual a universidade percebe e possibilita a inclusão dos seus alunos. São ações que criam um diferencial de oportunidades e atenção às demandas, como forma de aproximar os estudantes da uni- 
versidade e os serviços oferecidos, prevenindo e superando possíveis situações de inadaptação e insucesso, embora haja desafios no caminho (Antunes \& Faria, 2013; Abreu, Antunes, \& Almeida, 2012). A seguir, buscamos identificar, a partir das enunciações dos estudantes, os desafios enfrentados nos processos inclusivos na universidade.

\section{Método}

\section{Participantes}

Participaram no estudo oito estudantes com diferentes deficiências: deficiência visual (cegueira), deficiência física (ocasionada após traumatismo), deficiência auditiva (surdez profunda) e, ainda, estudantes com Dislexia e Síndrome de Asperger (necessidades educacionais especiais). Os participantes voluntariamente aceitaram conceder uma entrevista ou responder a um questionário online, abordando (ambos os instrumentos) a trajetória escolar e as percepções sobre a inclusão no ensino superior. Foram entrevistados três estudantes, sendo um do sexo masculino, com 25 anos de idade (participante A), uma participante do sexo feminino com 22 anos de idade (participante B) e uma terceira com 25 anos de idade (participante $\mathrm{C}$ ). Já o questionário online foi respondido por cinco estudantes, sendo o primeiro do sexo masculino, 25 anos de idade (participante D), o segundo do sexo masculino, 29 anos de idade (participante E), a terceira do sexo feminino, 41 anos de idade (participante F), a quarta do sexo feminino, 24 anos de idade (participante $G$ ), e a quinta do sexo feminino, 25 anos de idade (participante $\mathrm{H}$ ).

\section{Instrumentos}

Como instrumentos de recolha de dados foram realizados uma entrevista e um formulário online. A entrevista semi-estruturada teve como foco o conhecimento que os entrevistados possuem sobre o tema em estudo (Flick, 2009). A sua utilização visou identificar as percepções e as experiências dos interlocutores no ensino superior, destacando a reflexão, o conhecimento e as práticas dos participantes (Amado, 2013; Bauer \& Gaskell, 2012; Creswell, 2014; Flick, 2009). O roteiro da entrevista abordou como domínios: (a) o percurso escolar; (b) percepções sobre a deficiência; (c) a experiência pessoal na universidade; e (d) a inclusão e seus desafios na universidade (barreiras e formas de superação). O segundo instrumento utilizado foi um questionário online (modelo Google docs), o qual abordou, de uma forma mais direta, os mesmos domínios da entrevista.

\section{Procedimentos}

Para a realização do estudo foi solicitada a autorização junto ao Gabinete para a Inclusão da universidade que promoveu o contato dos pesquisadores com os estudantes. A seguir, o convite para a entrevista foi feito individualmente aos estudantes tendo três deles aceito. As entrevistas realizaram-se ao longo dos meses de setembro e outubro de 2014, em espaços da universidade. As entrevistas duraram entre 30 minutos e uma hora, e foram gravadas em equipamento de áudio com autorização dos participantes. Foram feitos esclarecimentos sobre os objetivos do estudo, a confidencialidade dos dados e o anonimato. Dada a reduzida adesão de participantes às entrevistas, solicitou-se o apoio do gabinete para uma extensão da coleta de dados através de questionário online. O instrumento foi enviado aos estudantes diretamente pelo GPI, por meio de mensagem eletrônica com orientações sobre a pesquisa e o preenchimento, além do link de acesso ao formulário.

Após a coleta dos dados, cada uma das entrevistas foi transcrita integralmente e o processo de análise buscou identificar unidades e categorias temáticas, respeitando as percepções dos estudantes e os objetivos do estudo. O mesmo procedimento foi realizado em relação aos questionários online. Os instrumentos foram analisados individualmente e a seguir, entre eles, procurou-se identificar características gerais ou específicas elencadas no quadro dos objetivos do estudo.

\section{Resultados}

Como já afirmado, os dados aqui apresentados e discutidos reportam parte de um estudo mais amplo, enquadrado nas trajetórias de desenvolvimento de estudantes com deficiências no ensino superior, recortando dados ligados à realidade de universidades no Brasil e em Portugal. Aqui apresentamos as percepções dos estudantes portugueses sobre os serviços de apoio na universidade, organizadas em três questões: (a) a percepção sobre os serviços de apoio à inclusão na universidade, (b) as barreiras encontradas, e (c) as sugestões que apontam para a superação.

\section{A percepção sobre os serviços de apoio à inclusão na universidade}

Os relatos dos estudantes sobre a percepção quanto à atuação dos serviços de apoio à inclusão, na universidade, puderam ser agrupados em duas categorias: atuação positiva e atuação insuficiente e/ou limitada. Os estudantes que reportaram uma avaliação positiva da atuação do gabinete mencionaram o atendimento a demandas individuais e o apoio em casos específicos, como no processo de inscrição e adequação de materiais:

Eles são bons a fazer o trabalho deles. Eles dão-nos ajudas quando nós precisamos. Eu precisei de ajuda na inscrição porque eu era especial. E foi só esse apoio até agora e eles me atenderam (participante A - Síndrome de Asperger).

Eu sempre preciso de digitalização de materiais e eles fazem digitalização dos documentos, passa para PDF e depois 
no OCR para ficar acessível (participante C - Deficiência visual).

O gabinete para a inclusão faz tudo o que podem para que os nossos direitos sejam assegurados (participante D Deficiência física).

Já os estudantes que apontaram como insuficiente e/ou limitada a atuação do gabinete, destacaram a necessidade de mais profissionais para atendimento às demandas surgidas nas atividades acadêmicas, bem como questões administrativas (recursos financeiros e pessoal) ou ao ambiente social de maior ou menor aceitação da diferença:

O GPI não pode fazer muito. Será que não devia ser maior? Ter mais especialistas, mais autoridade. O GPI nem sempre pode resolver. Eu precisei de ajuda para escrever meu relatório de estágio e não tinha ninguém para me ajudar. Aqui não tinha e nunca houve ninguém para ajudar com uma correção. Mas não devia ser assim. Eles deviam ter alguém ali o ano inteiro a corrigir, a acompanhar as atividades dos alunos com dificuldade, para apoiar e acompanhar e não há. Efetivamente eles deviam ter gente com essa especificidade, eles deviam ter terapeutas da fala, ter psicólogos, disponibilizar isso para os alunos. E não disponibilizam (participante B - Dislexia).

Recorro ao GPI, que não consegue solucionar todos os nossos problemas, quer pela falta de fundos monetários, que vai implicar o número de funcionários, quer por não possuir um poder mágico que faça as pessoas aceitarem-se umas às outras (participante G - Deficiência visual).

A universidade ao criar um sistema de apoio, organiza ações com o objetivo de estabelecer uma política permanente de atenção às pessoas com deficiência, procurando a promoção da igualdade de oportunidades e a disponibilização de condições para o envolvimento destes estudantes nas atividades de vida acadêmica. No entanto, as dificuldades e desafios fazem com que as percepções sobre as referidas ações se limitem ao atendimento de algumas demandas, normalmente mais ligadas a questões pontuais e meramente adaptativas. De acrescentar que os estudantes reconhecem o valor das iniciativas de mediação, que visam equacionar problemas e promover oportunidades. Ao mesmo tempo, identificam limites e desafios a serem enfrentados pelo programa de apoio, no que se refere à sua autonomia perante a gestão central, à carência de profissionais especializados em inclusão, assim como ao limite de seu escopo de influência em relação aos professores.

\section{As barreiras encontradas para a realização das atividades acadêmicas}

No que se refere ao tema das barreiras encontradas para a realização das atividades acadêmicas elencamos as seguintes categorias: a socialização, as dificuldades provo- cadas pela condição decorrente da deficiência, a falta de serviços específicos no apoio, e a relação com os professores. A categoria 'relação com os professores' se desdobra em três destaques: a inflexibilidade, a avaliação e o preconceito.

Ainda tem a falta de técnicos. Pessoas como psicólogos, terapeutas e pessoas que acompanhem os estudantes e possam apoiar no que precisa. Um conjunto de pessoas que deviam existir para que nós existíssemos melhor. Para que nós pudéssemos brilhar melhor, com mais facilidade, com a ajuda que merecemos... O preconceito dos professores. Porque acho que no fundo é um preconceito. Quando a gente não entende uma coisa e não quer saber dela é um preconceito. E é esse o problema dos professores. O preconceito que eles têm com os alunos (participante B - Dislexia).

Importa referir que, neste grupo de estudantes, um deles expressou que não percebe qualquer barreira para a realização das suas atividades acadêmicas: "Não, não tenho qualquer barreira ao desenvolvimento do meu estudo" (participante F- Deficiência auditiva).

O espaço da universidade tem fundamental importância para a formação de consciências inclusivas, cujas ações podem ter impacto em diferentes contextos sociais. Uma universidade inclusiva necessita lidar com um perfil muito diferenciado de demandas, negando categorizações atribuídas universalmente (Mantoan, 2008). Interessa-nos a construção de um ambiente educacional em que as diferenças não mais sejam negadas e desvalorizadas (Valle \& Connor, 2014). Para isso, a adoção de uma cultura inclusiva se faz necessária, perpassando desde a formação do professor e técnicos, assim como o investimento de recursos com a finalidade de promover as adequações necessárias, e ainda, a ampla discussão do tema nos diferentes espaços de formação acadêmica. Este debate pode, inclusive, ajudar os próprios estudantes a solicitarem mais espontaneamente os apoios junto dos serviços e junto dos professores sem se sentirem inferiorizados.

\section{As sugestões que apontam para a superação dos desafios e dificuldades}

O questionamento a seguir solicitava aos estudantes, segundo as barreiras apontadas, sugestões para a superação. Assim, foram mencionados pelos estudantes temas que agrupamos nas seguintes categorias: formação e acessibilidade dos espaços. No tocante à formação, mencionaram:

A formação para lidar com a diferença, para lidar com pessoas e ainda mais, para lidar com pessoas com deficiência. $E$ isso precisa ser um grande foco, saber o que é e o que precisa ser feito. Mas se não conseguirmos mudar a mentalidade, a essência, não podemos fazer muito (participante B - Dislexia).

E eu acho que a inclusão no ensino superior, na escola e no mercado de trabalho devia ser... devia ser aquilo que nós 
encontramos nos livros e diz que a inclusão é basicamente a igualdade para todos e que todos terem as mesmas oportunidades, e se calhar, isso devia passar mais à prática (participante C - Deficiência visual).

A minha sugestão seria a universidade apoiar o aluno com deficiência até ele atingir o seu objetivo, a atividade profissional qualificada (participante F - Deficiência auditiva).

O meu conselho foca-se na difusão de informação, mas não apenas através de cartas, com palestras com as pessoas que estarão em contato com os alunos com deficiência, onde lhe possam explicar o porquê das deficiências, como agir (participante D - Deficiência física).

As práticas de inclusão, entendidas em uma perspetiva ética, se estabelecem nas relações com o outro e, ao longo da história, favorecem a colaboração, o diálogo, a valoração positiva, que resulta em aceitação (Valsiner, 2012). Entretanto, ainda não é consensual no espaço da universidade que a inclusão é um direito inalienável dos estudantes tendo em vista o êxito de todos em sua trajetória de formação. Neste ponto, importa destacar a necessidade de formação dos professores e dos serviços em geral da universidade, como vemos na sugestão a seguir:

Pode ser melhorada se os professores procurassem ter uma formação mais intensiva em alunos com deficiência, e deixassem os preconceitos de lado. Procurando ver os alunos como indivíduos, seres únicos pelas suas características (participante G - Deficiência visual).

Sim, mudar a mentalidade fechada dos professores e a sua inflexibilidade à diferença (participante G - Deficiência visual).

A relação com os professores, por vezes traduzida em eventos de inflexibilidade, é uma barreira enfrentada por todos os participantes da pesquisa, permitindo inferir que se trata de uma dificuldade frequente e bastante enraizada. Estudos na área indicam que grande parte das dificuldades de inclusão relatadas por estudantes universitários decorre do seu relacionamento com professores (Abreu, Antunes, \& Almeida, 2012; Antunes \& Faria, 2013; Fernandes \& Almeida, 2007; Fernandes, Almeida, \& Mourão, 2007). Dos responsáveis pelo trabalho cotidiano com os estudantes, espera-se então o envolvimento no debate e a reflexão sobre o papel da inclusão no desenvolvimento pessoal e social dos sujeitos (Mantoan, 2008). Percebemos com facilidade que a cultura da inclusão está insuficientemente disseminada entre os professores na universidade. Conciliar as práticas inclusivas e a vocação meritocrática que orienta a atuação docente no ensino superior demanda iniciativas criativas e problematizadoras, e particularmente a formação continuada de docentes e profissionais.

Por fim, ao referirem a acessibilidade dos espaços, um destaque exemplifica a preocupação destes estudantes:
Se calhar alguns serviços estarem mais acessíveis, com acesso mais... talvez mais próximos. Há algumas coisas em termos de espaços físicos que poderiam ser melhoradas ou redefinidas, mas eu sei que nem sempre é fácil, porque fazer muitas mudanças no espaço físico nem sempre é possível. Alguns serviços estarem mais acessíveis, cantina, bar (participante C - Deficiência visual).

O cuidado com a acessibilidade, entendida como o livre e fácil acesso e ingresso aos espaços (Caiado, 2010), e as condições de mobilidade segura e ampla, são ações inclusivas básicas. Como destaca Fischer (2014), normalmente as universidades disponibilizam os recursos de acesso e mobilidade aos espaços visitados com maior frequência pelos estudantes, restringindo assim deslocamentos e atividades. As dificuldades fazem com que os estudantes enfrentem desafios para chegar ao campus, ir de um espaço a outro e, ainda, sair da universidade em condições adequadas e seguras. Nestas circunstâncias, além de riscos à integridade física, dificuldades relacionadas à acessibilidade geram nos estudantes constrangimentos que alimentam significados relacionados à desvantagem, à diferença e à exclusão. A diferença passa a ser percebida como negativa, e impeditiva do exercício autônomo de atividades e de inserção nas práticas cotidianas, comprometendo, por isso, o sentimento de cidadania.

\section{Discussão}

Os dados recolhidos junto a este pequeno grupo de estudantes permitiu-nos tecer algumas reflexões em torno de temas emergentes: (a) os serviços de apoio à inclusão disponibilizados pela universidade, (b) as barreiras presentes à sua inclusão, e (c) os desafios percebidos para a inclusão de estudantes com deficiência no ensino superior.

No que se refere ao tema dos serviços de apoio disponibilizados pela universidade, verificamos que as enunciações dos estudantes revelam o reconhecimento da importância dos serviços em sua trajetória académica, o que vai ao encontro de outros estudos sobre o tema (Abreu, Antunes, \& Almeida, 2012; Antunes \& Faria, 2013; Bisinoto \& Marinho-Araújo, 2014). Revelam, ainda, a necessidade de ampliação e qualificação dos referidos serviços, em função das necessidades específicas dos estudantes, como forma de tornar a experiência acadêmica mais proveitosa (Antunes \& Faria, 2013).

A ampliação dos serviços, segundo mencionado pelos estudantes, reporta-se à disponibilização de especialistas e técnicos que possam apoiá-los e acompanhá-los nas atividades. A crença manifestada é de que a ampliação das ações dos gabinetes ou serviços de apoio pode oferecer igualdade de oportunidades aos estudantes, sobretudo na transição do ensino médio para o ensino superior, reconhecido como mais exigente e complexo (Coulon, 2008; Fernandes \& Almeida, 2007). 
No tocante às barreiras percebidas à inclusão na universidade, o discurso dos estudantes reportou importantes fatores: a falta de oportunidades mais amplas de reconhecimento e aceitação, sobretudo por parte dos professores. De forma mais específica, a relação com os professores, por vezes, traduz-se em eventos de inflexibilidade frente às demandas dos estudantes que se traduzem, por exemplo, em práticas de avaliação inadequadas ou preconceitos relativamente a estes estudantes. Estudos na área indicam que as maiores dificuldades relatadas por estudantes universitários, face à inclusão, relacionam-se com o seu relacionamento interpessoal com professores e colegas (Abreu, Antunes, \& Almeida, 2012; Antunes \& Faria, 2013; Fernandes \& Almeida, 2007; Fernandes, Almeida, \& Mourão, 2007). Os estudantes citaram, ainda, a falta de serviços especializados nos sistemas de apoio que pudessem facilitar a sua participação mais ativa nas atividades acadêmicas, por exemplo a falta de psicólogos, fonoaudiólogos, pedagogos e técnicos que atuem na adequação de materiais à sua aprendizagem.

A última questão reporta às sugestões para a superação das barreiras enfrentadas. Os respondentes assinalam os desafios da formação, da acessibilidade e adequação dos espaços, e, ainda, das ações de apoio e informação. Ao mencionar a formação, destacam sobretudo a necessidade de formação de professores e funcionários, aumentando as suas competências para prover respostas adequadas à presença dos estudantes com deficiência, no espaço universitário. O alerta é para a superação de discursos de preconceito e para a adoção de práticas mais inclusivas no cotidiano da universidade (Antunes \& Faria, 2013). A aceitação e participação nos grupos pode representar um importante estímulo à permanência e aproveitamento dos estudos, além de favorecer o sentimento de pertença (Antunes \& Almeida, 2012; Bisinoto \& Marinho-Araújo, 2014; Fischer, 2014; Silva, Ferreira, \& Ferreira, 2014).

A acessibilidade/adequação dos espaços destaca-se como outro importante desafio a ser acolhido pela universidade: tornar seus espaços mais adequados e acessíveis às pessoas com dificuldades de mobilidade ou deficiência visual. Além de uma questão de segurança e prevenção de acidentes, a adequação dos espaços pode representar também oportunidades de socialização em espaços que têm essa característica, como os bares e cantinas da universidade (Abreu \& Antunes, 2011; Fernandes \& Almeida, 2007).

Outro destaque foi dado à questão da informação. Por um lado, a necessidade de informação aos estudantes com deficiência versando sobre os seus direitos e deveres na universidade, em particular em torno da realização das suas atividades acadêmicas. Antecipa-se que, se adequadamente informados das rotinas e atividades a realizarem na universidade, estes estudantes podem sentir-se mais seguros e confiantes, favorecendo neles o desenvolvimento de expectativas mais positivas em relação à universidade e ao curso, assim como estimulando o desenvolvimento da sua autonomia. Por outro lado, destacamos que a informação sobre as características e especificidades demandadas por estes estudantes junto dos colegas e professores se assume como um importante mecanismo de inclusão, permitindo aos estudantes e docentes encontrarem formas mais adequadas de trabalho, que tenham em conta a diversidade estudantil (Abreu \& Antunes, 2011; Fernandes \& Almeida, 2007). Cremos que as relações construídas na presença de informações reais sobre demandas, possibilidades e limites tendem a ser mais seguras e produtivas, resultando em melhor aproveitamento da experiência acadêmica (Almeida, Antunes, \& Faria, 2013; Bucuto, Almeida, \& Araújo, 2014; Coulon, 2008; Dias \& Lopes de Oliveira, 2013).

De forma geral, a imersão no tema e os resultados da pesquisa apontam para a relevância de ampliar a visibilidade dos processos inclusivos na universidade. Percebemos, por meio das experiências narradas pelos estudantes, os impasses, os apoios recebidos, os obstáculos enfrentados, assim como a necessária ampliação do debate sobre o tema que possa dar maior visibilidade as práticas inclusivas no espaço da universidade.

\section{Considerações finais}

A inclusão no ensino superior é hoje uma realidade para muitos jovens que provêm de diversas matrizes socioculturais e que expressam distintas necessidades. Por isso, permanece como um desafio para a universidade responder de forma positiva à demanda crescente dos estudantes com deficiência. Esta demanda tem justificado, em Portugal, a criação de serviços de apoio à inclusão, por parte das instituições de ensino superior.

O objetivo do estudo foi alcançado, uma vez que foi possível conhecer o que pensam e sentem os estudantes com deficiência, frente aos serviços existentes, e as suas sugestões para a melhor integração e aproveitamento da experiência universitária. Cremos que iniciativas com tal natureza são fundamentais para qualificar os serviços e aumentar chances de sucesso acadêmico. Os destaques apontados pelos estudantes, de forma geral, constituem desafios que podem ampliar e qualificar o sistema de apoio à inclusão na universidade, favorecendo a sua permanência e aproveitamento (Abreu \& Antunes, 2011; Almeida, Costa, Alves, Gonçalves, \& Araújo, 2012; Anache, 2007; DelPrette \& DelPrette, 1998; Fernandes \& Almeida, 2007).

Neste estudo, foram destacadas a necessidade de formação do corpo docente e de servidores e a criação de mecanismos de valorização de tal formação. São desafios também a promoção de ações (amplas e específicas) de sensibilização para questões ligadas à aceitação da diversidade e combate a atitudes de preconceito no cotidiano. A universidade precisa destacar-se como espaço de exercício da cidadania e transformador de valores, promovendo a investigação e ampliando o debate sobre a temática, como primeiro passo a práticas inclusivas mais assumidas institucionalmente (Andrade, 2010; Olive, 2002; Severino, 2008; Sousa Santos, 2005; Trindade, 2001).

Por outro lado, também constitui desafio a disponibilização de serviços de apoio especializados para acompa- 
nhamento processual dos estudantes com deficiências que demandam ajudas específicas dos campos da Psicologia, Pedagogia ou recursos técnicos. Um destaque é a disponibilização de apoio e informação aos estudantes sobre a universidade e seu funcionamento, desde o momento da inscrição, proporcionando maior familiarização com o ambiente e funcionamento, gerando expectativas positivas em relação ao ensino superior e a adoção de atitudes mais ativas face aos desafios dessa nova etapa de estudos (Abreu \& Antunes, 2011; Fernandes \& Almeida, 2007). Esse apoio possibilita, ainda, o exercício da autonomia, entendido como característica relevante do ensino superior (Bisinoto \& Marinho-Araújo, 2014; Fischer, 2014; Silva, Ferreira, \& Ferreira, 2014).

A terminar, embora se caracterizem como importante iniciativa, os serviços de apoio precisam ampliar e diversificar suas ações no espaço universitário. Incluímos, aqui, as ações de sensibilização e reflexão sobre cidadania, diversidade e preconceito; as ações de formação continuada de professores e servidores; a valorização e adequação dos espaços da universidade enquanto oportunidades de socialização e de autonomia dos estudantes, aproximando-os assim da rotina e demandas características do trabalho com estudantes universitários. Entendemos que promover a inclusão nesse nível de ensino representa um desafio, permeado por diversas dificuldades: a sensibilização da comunidade universitária; a desconstrução de crenças e preconceitos contra aqueles que são percebidos como dotados de uma capacidade "menor" de aprendizagem devido à deficiência; a desconstrução das autoimagens institucionais assentes apenas na meritocracia; o respeito às diferenças humanas; e o amplo envolvimento da comunidade acadêmica na ética da inclusão. Além da sensibilização dos atores e da luta contra os preconceitos e a desinformação, identifica-se uma ampla necessidade de adequar a formação docente, de assegurar a aquisição e manutenção de equipamentos e o desenvolvimento e a especialização dos serviços de apoio no espaço universitário.

Assim, e apesar da limitação decorrente do número reduzido de participantes, este estudo se mostrou importante e possibilitou a recolha de dados relevantes sobre a inclusão no ensino superior. Estudos futuros na temática, procurando grupos mais expressivos e representativos de estudantes, poderão ampliar a discussão, focando em temáticas específicas que emergiram como a formação docente, as práticas de ensino e de avaliação, bem como, as relações entre professores e estudantes com deficiências. As iniciativas em curso se fazem importantes na luta contra a estigmatização dos estudantes com deficiência, havendo ainda importantes desafios para tornar o espaço universitário amplamente democrático e capaz de incluir as diferenças e demandas de todos os estudantes (Sousa, Soares, \& Evangelista, 2003). No fundo, à medida que a universidade recebe mais estudantes com deficiência, ela acaba por ser desafiada a tornar-se cada vez mais inclusiva.

\section{Referências}

Abreu, M., Antunes, A. P., \& Almeida, L. S. (2012). A Inclusão no Ensino Superior: Estudo exploratório numa Universidade Portuguesa. Revista da Educação Especial e Reabilitação, 19, 107-120.

Abreu, M. (2013). Alunos com necessidades educativas especiasi: Estudo exploratório sobre a inclusão no ensino superior. Dissertação de Mestrado, Universidade da Madeira, Funchal, Portugal.

Abreu, M. \& Antunes, A. P. (2011, setembro). Alunos com necessidades educativas especiais: Estudo de caso no ensino superior. Comunicação apresentada no XI Congreso Internacional Galego-Português de Psicopedagoxia. Universidade da Coruña. Espanha.

Almeida, L. S., Costa, A. R., Alves, F., Gonçalves, P., \& Araújo, A. (2012). Expetativas académicas dos alunos do ensino superior: Construção e validação de uma escala de avaliação. Psicologia, Educação e Cultura, 16(1), 70-85.

Amado, J. (2013). Manual de Investigação Qualitativa em Educação. Coimbra: Imprensa da Universidade de Coimbra, Portugal.

Anache, A. (2007). O psicólogo nas Redes de Serviços de Educação Especial: Desafios em face da inclusão. Em A. M. Martínez (Org.), Psicologia Escolar e Compromisso Social (pp.121-144). Campinas, São Paulo: Alínea.

Andrade, C. Y. (2010). Acesso ao ensino superior no Brasil: Equidade e desigualdade social. Revista Ensino Superior Unicamp, 18- 27.

Antunes, A. P. \& Faria, C. P. (2013). A universidade e a pessoa com necessidades especiais: estudo qualitativo sobre perceções de mudança social, institucional e pessoal. Indagatio Didactica, 5, (2), 475-488.

Bauer, M. W. \& Gaskell, G. (2012). Pesquisa qualitativa com texto, imagem e som: Um manual prático. Petropólis: Vozes.

Bisinoto, C. \& Marinho-Araújo, C. M. (2014). Sucesso Acadêmico na Educação Superior: Contribuições da Psicologia Escolar. Revista E-Psi, 4(1), 28-46.

Bucuto, M. C., Almeida, L.S., \& Araújo, A. M. (2014). Expetativas acadêmicas de estudantes universitários em Moçambique: validação de uma versão do questionário de perceções acadêmicas (QPA - Expetativas). Em L. S. Almeida, A. M. Araújo, A. R. Franco \& D. L. Soares (Orgs), Cognição, Aprendizagem e Rendimento: I Seminário Internacional (pp.35-52). Universidade do Minho, Portugal.

Caiado, K. R. M. (2010). Trajetórias escolares de alunos com deficiência (Ed). São Paulo: EDUFSCAR. 
Coulon, A. (2008). A condição de estudante: a entrada na vida universitária. Salvador, BA: UDUFBA.

Creswell. J. W. (2014). Investigação Qualitativa e Projeto de Pesquisa: Escolhendo entre cinco abordagens. Porto Alegre: Penso.

Del Prette, Z. A. P. \& Del Prette, A. (1998). Desenvolvimento interpessoal e educação escolar: o enfoque das habilidades sociais. Temas em Psicologia, 6, (3), 205-215.

Dias, S. \& Lopes de Oliveira, M. C. S. (2013). Deficiência Intelectual na perspectiva histórico-cultural: Contribuições ao estudo do desenvolvimento adulto. Revista Brasileira de Educação Especial, 19 (2), 169-182.

Faria, C. P. (2012). Inclusão de alunos com necessidades educativas especiais no ensino superior: Estudo exploratório sobre as perceções dos docentes. Dissertação de Mestrado, Universidade da Madeira, Funchal, Portugal.

Fernandes, E., \& Almeida, L. (2007). Estudantes com deficiência na universidade: Questões em torno da sua adaptação e sucesso acadêmico. Revista da Educação Especial e Reabilitação, 14, 7-14.

Fernandes, E. A., Almeida, L. S., \& Mourão, J. (2007). Inclusive university education viewed by the non disabled students. The Internacional Journal of Diversity in Organizations, Communities and Nations, 7 (1), 169-178.

Flick, U. (2009). Introdução à Pesquisa Qualitativa. Porto Alegre: Artmed.

Fischer, J. (2014). Inclusão de acadêmicos com deficiência na universidade: Possibilidades e desafios. Em: S. E. Orrú (Org.), Para além da educação especial: Avanços e desafios de uma educação inclusiva (pp. 87-102). Rio de Janeiro: Wak editora.

Mantoan, M. T. E. (2013). Diferenciar para incluir ou para excluir? Por uma pedagogia da diferença. Disponível: http:// www.diversa. org.br/artigos/artigos.php?id=2879\&/diferenciar_para_incluir_ ou_para_excluir_por_uma_pedagogia_da_diferença. Acesso em 20.06.2014.

Marinho-Araújo, C. M. (2009). Psicologia Escolar na educação superior: novos cenários de intervenção e pesquisa. Em C. M. Marinho-Araújo (Org.), Psicologia Escolar: novos cenários e contextos de pesquisa, formação e prática (pp. 155-202). Campinas-SP: Alínea.

Marinho-Araújo, C. M. (2011). Psicologia Escolar e educação superior: construindo possibilidades diferenciadas de atuação. Em R. S. L. Guzzo \& C. M. Marinho-Araújo (Orgs.), Psicologia Escolar: identificando e superando barreiras (pp.130-156). Campinas-SP: Alínea.
Morejón, K. \& Garcia, L.R. (2010, novembro). A inclusão de pessoas com deficiência no ensino superior público do estado do Rio Grande do Sul - RS. Comunicação apresentada no Congresso Ibero-americano de educação: Metas 2011. Universidade de Buenos Aires, Argentina.

Olive, A. C. (2002). Histórico da educação Superior no Brasil. Em M. S. A. Soares (Org), A educação superior no Brasil. Brasília: CAPES.

Pires, L. M. F. S. A. (2007). A caminho de um ensino superior inclusivo? A experiência e percepção dos estudantes com deficiência - estudo de caso. Dissertação de Mestrado, Faculdade de Motricidade Humana, Universidade Técnica de Lisboa, Lisboa, Portugal.

Portugal (1976). Constituição da República Portuguesa. 1976. Lisboa: Assembleia da República.

Portugal (1986). Lei n. ${ }^{\circ} 46 / 1986$, de 14 de outubro de 1986. Dispõe sobre as Bases do Sistema Educativo. Lisboa: Ministério da Educação.

Portugal (2003). Lei n. ${ }^{\circ}$ 37/2003, de 22 de agosto de 2003. Dispõe sobre as Bases para o Financiamento do Ensino Superior em Portugal. Lisboa: Ministério da Educação.

Portugal (2006). Lei $n .^{\circ}$ 46/2006, de 28 de agosto de 2006. Dispõe sobre a não discriminação das pessoas com base na deficiência e no risco agravado à saúde. Lisboa: Assembleia da República.

Portugal (2008). Decreto-Lei n. ${ }^{\circ}$ 03/2008, de 07 de janeiro de 2008. Dispõe sobre os apoios especializados a prestar na educação. Lisboa: Ministério da Educação.

Ressurreição, S. B. (2013). Estudantes universitários indígenas: histórias de rupturas e transições. Exame de qualificação de Doutorado, Universidade Federal da Bahia, Salvador, BA.

Santos, C. S. (2013). Políticas de acesso e permanência de alunos com deficiência em Universidades Brasileiras e Portuguesas. Tese de Doutorado, Faculdade de Educação, Universidade Federal de Uberlândia, Uberlândia.

Seixas, A. M. (2003). Políticas educativas e ensino superior em Portugal. Coimbra: Quarteto.

Severino, A. J. (2008). O ensino superior brasileiro: novas configurações e velhos desafios. Educar, 31, 73-89.

Silva, S. L. R., Ferreira, J. A. G., \& Ferreira, A. G. (2014). Vivências no ensino superior e percepções de desenvolvimento: Dados de um estudo com estudantes do ensino superior politécnico. Revista E-Psi, 4(1), 28-46.

Sousa, A. M., Soares, D. L. e Evangelista, G. B. M. G. (2003). A Universidade de Brasília e a inclusão do aluno com necessidades educativas especiais. Linhas Críticas, 9, (16), 105-126. 
Sousa Santos, B. (2005). A Universidade no século XXI: Para uma reforma democrática e emancipatória da Universidade. São Paulo: Cortez.

Trindade, H. (2001). Universidade, Ciência e Estado. Em: H. Trindade (Org.), Psicologia Social Contemporânea. Petrópolis: Vozes.

Valle, J. W. \& Connor, D. J. (2014). Ressignificando a deficiência: Da abordagem social às práticas inclusivas na escola. Porto Alegre: Penso.
Valsiner, J. (2012). Fundamentos da Psicologia Cultural: mundos da mente, mundos da vida. Porto Alegre: Artmed.

Recebido em: 04/07/2015

Reformulado em: 29/01/2016

Aprovado em: 24/06/2016

\section{Sobre os autores}

Ana Claudia Rodrigues Fernandes (anacrff@gmail.com)

Doutora em Processos de Desenvolvimento Humano e Saúde - PGPDS-UnB.

Maria Cláudia Santos Lopes de Oliveira (mcsloliveira@gmail.com)

Doutora em Educação. Professora Associada da Universidade de Brasília. Instituto de Psicologia - IP - UnB.

Leandro da Silva Almeida (leandro@ie.uminho.pt)

Doutor em Psicologia. Professor Catedrático da Universidade do Minho. Instituto de Educação - Uminho.

Trabalho originário de estágio doutoral (Doutorado Sanduíche) da primeira autora, sob orientação da segunda autora e coordenação do terceiro autor, realizado no período de agosto a dezembro de 2014 na Universidade do Minho, Portugal, com apoio Capes. 